\title{
ERRATUM: Comparison of Surgery Plus Chemotherapy and Palliative Chemotherapy Alone for Advanced Gastric Cancer with Krukenberg Tumor
}

\author{
Jang Ho Cho, MD', Jae Yun Lim, MD, PhD', Ah Ran Choi, MD', Sung Min Choi, MD', Jong Won Kim, MD², \\ Seung Ho Choi, MD, PhD², Jae Yong Cho, MD, PhD' \\ ${ }^{1}$ Division of Medical Oncology, Department of Internal Medicine, \\ ${ }^{2}$ Department of Surgery, Gangnam Severance Hospital, Yonsei University College of Medicine, Seoul, Korea
}

In this article, a grant number error was found in the Acknowledgments section. The corrected version of Acknowledgments is as follows.

This research was supported by a faculty research grant of Yonsei University College of Medicine for 2009 (6-2009-0173) and the Basic Science Research Program through the National Research Foundation of Korea funded by the Ministry of Education, Science, and Technology.

The authors would like to apologize for any inconvenience caused.

*DOI of original article: https:// doi.org/10.4143/crt.2013.175 